\title{
Comparative Estimation of Major Iridoid Glucosides from Different Parts of Incarvillea emodi
}

\author{
Ajay Rana, ${ }^{1}$ Harsh Pratap Singh, ${ }^{1}$ and Devendra Dhyani ${ }^{2}$ \\ ${ }^{1}$ Hill Area Tea Science Division, Institute of Himalayan Bioresource Technology, Council of Scientific and Industrial Research, \\ Himachal Pradesh, Palampur 176061, India \\ ${ }^{2}$ Floriculture Division, Institute of Himalayan Bioresource Technology, Council of Scientific and Industrial Research, \\ Himachal Pradesh, Palampur 176061, India
}

Correspondence should be addressed to Harsh Pratap Singh, hps2152@yahoo.com

Received 1 February 2012; Accepted 27 February 2012

Academic Editors: G. R. Dennis, J. Matysiak, L. Nahar, and T. Richard

Copyright ( $) 2012$ Ajay Rana et al. This is an open access article distributed under the Creative Commons Attribution License, which permits unrestricted use, distribution, and reproduction in any medium, provided the original work is properly cited.

Incarvillea emodi (Bignoniaceae) is a rich source of bioactive iridoid glucosides. This plant contains two major iridoid glucosides: plantarenaloside, a neurotropic compound, and boschnaloside, a strong antibacterial compound. Here, in this study we have developed a simple and fast HPLC-DAD method for the total comparative estimation of these two major iridoids from different parts of Incarvillea emodi. A linear calibration curve $\left(r^{2}=0.999\right)$ for both iridoid glucosides in varying range $(15.6-500 \mu \mathrm{g} / \mathrm{ml})$ is obtained. The limit of detection (LOD) and limit of quantification (LOQ) for plantarenaloside were $11.4 \mathrm{ng}$ and $38 \mathrm{ng}$ and for boschnaloside were $22.8 \mathrm{ng}$ and $76 \mathrm{ng}$, respectively. The shoots, roots, and flowers of Incarvillea emodi have a combined presence of $7.66,1.22$, and 6.99 percent of these iridoid glucosides on dry weight basis. In shoots, plantarenaloside shows complete dominance $(6.78 \%)$ over boschnaloside $(0.88 \%)$, and a reversal of this trend was observed in case of flowers where boschnaloside shows complete dominance $(6.12 \%)$ over plantarenaloside $(0.87 \%)$. The roots contain $1.19 \%$ and $0.03 \%$ of both iridoids, respectively.

\section{Introduction}

Incarvillea emodi (Bignoniaceae) is a wild flowering plant found mainly at high altitudes of the western Himalayas. This plant has attracted little scientific attention in the past because of its sparse availability due to erosion of natural habitat. Dwindling habitat and lack of concern for preservation through cultivation and other means make it cited as endangered species. In our laboratory, chemical investigation of the whole plant has shown it to be a major source of two naturally occurring bioactive iridoid glucosides, namely, plantarenaloside (1) and boschnaloside (2). Iridoids exhibit a wide range of bioactivities including hepatoprotective, cardiovascular, antihepatotoxic, chlorectic, hypoglycemic, anti-inflammatory, antispasmodic, antitumor, antiviral, immunomodulator, and purgative activities [1-5].

The iridoids isolated from this plant are bioactive compounds with neurotrophic [6] and antibacterial [7] activity. In the present study, a new and rapid high pressure liquid chromatography (HPLC) method with diode array detector was reported for the quantification and determination of these iridoid glucosides in plant organs. Previously plantarenaloside has been shown to have tenfold dominance over euphroside in Penstemon rydbergii (Scrophulariaceae) [8]. Here in case of Incarvillea emodi (Bignoniaceae) plantarenaloside has had dominance over boschnaloside in case of shoots, but in flowers it was otherwise. In recent years, there has been an increased interest towards the development of new HPLC method for estimation and quantification of iridoids [9-13]. In the present study we have developed a simple fast and accurate LC-PDA method for the quantification of major iridoid glucosides plantarenaloside and boschnaloside (Figure 1) from different parts of Incarvillea emodi.

\section{Experimental}

2.1. Plant Material and Reagents. The plant material was collected during February 2010 (flowering season) from the experimental farm of the Institute of Himalayan Bioresource Technology where it was domesticated by Dr. D. Dhyani of Floriculture Division. A voucher sample was deposited in 
TABLE 1: Showing linear regression equation and LOD and LOQ of iridoids.

\begin{tabular}{lcccc}
\hline Iridoids & Regression equation & $r^{2}$ & Test range & LOD \\
\hline Plantarenaloside & $Y=6888 x-8609$ & 0.999 & $15.6-500 \mu \mathrm{g} / \mathrm{mL}$ & $11.4 \mathrm{ng}$ \\
Boschnaloside & $Y=7776 x-8498$ & 0.999 & $15.6-500 \mu \mathrm{g} / \mathrm{mL}$ & $38 \mathrm{ng}$ \\
\hline
\end{tabular}

TABLE 2: Repeatability and reproducibility of interday and intraday precision $(n=6)$.

\begin{tabular}{lccccc}
\hline \multirow{2}{*}{ Iridoids } & \multirow{2}{*}{ Amount } & \multicolumn{2}{c}{ Intraday variability } & \multicolumn{2}{c}{$\begin{array}{c}\text { Interday variability } \\
\text { Mean }\end{array}$} \\
\hline \multirow{3}{*}{ Plantarenaloside } & $125 \mu \mathrm{g} / \mathrm{mL}$ & 818338 & 0.26 & 816007 & 0.54 \\
& $250 \mu \mathrm{g} / \mathrm{mL}$ & 1647020 & 0.42 & 1644255 & 0.59 \\
& $500 \mu \mathrm{g} / \mathrm{mL}$ & 3475039 & 0.62 & 3449617 & 0.84 \\
\hline \multirow{3}{*}{ Boschnaloside } & $125 \mu \mathrm{g} / \mathrm{mL}$ & 924169 & 0.43 & 19175 & 0.55 \\
& $250 \mu \mathrm{g} / \mathrm{mL}$ & 1851650 & 0.28 & 390019 & 0.28 \\
& $500 \mu \mathrm{g} / \mathrm{mL}$ & 3923137 & 0.88 & 39005 & 0.54 \\
\hline
\end{tabular}
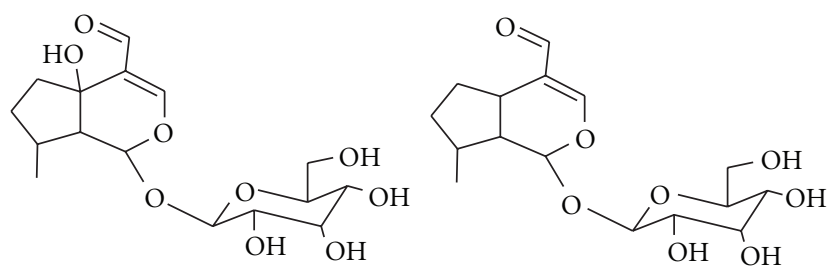

Plantarenaloside

Boschnaloside

Figure 1: Iridoid glucosides of I. emodi.

the herbarium section of the IHBT Palampur (PLP-5963). The plant material, roots, shoots, and flowers were dried in an oven at $40 \pm 5^{\circ} \mathrm{C}$. The dried plant material was than subjected to grind to form powder which was then stored in closed containers at room temperature $25 \pm 5^{\circ} \mathrm{C}$.

2.2. Isolation of Iridoids and Extraction. The iridoid glucosides were extracted from $80 \%$ aqueous methanol and further isolated from the partitioned butanolic fraction of extract of the shoot portion of Incarvillea emodi and by performing Silica gel (60-120 mesh size) column chromatography and their structures were established by ${ }^{1} \mathrm{H}$ - and ${ }^{13} \mathrm{C}$ NMR as reported earlier in our previous report [14] and comparison with the literature data $[15,16]$. All the solvents HPLC grade and analytical grade were purchased from S. d. Fine-Chem Ltd. (India).

2.3. HPLC Analysis. HPLC analysis was performed in Waters HPLC system with 2998 PDA detector and 2707 autosampler. The separation was achieved with Phenomenex Synergi MAX-RP $80 \mathrm{~A}$ column $(4.6 \times 250 \mathrm{~mm}, 4$ micron $)$ at $30^{\circ} \mathrm{C}$. A linear isocratic solvent system of methanol: water $(60: 40 \mathrm{v} / \mathrm{v})$ was used at a constant flow rate of $1 \mathrm{~mL} / \mathrm{min}$. In isocratic system, the concentration of the solvents remains constant throughout the run. The injection volume was $10 \mu \mathrm{L}$ and the compounds were detected at $247 \mathrm{~nm}$.
2.4. Sample Preparation. Standard stock solutions (internal standard) of the plantarenaloside and boschnaloside were prepared at a concentration of $1.0 \mathrm{mg} / \mathrm{mL}$ with HPLC grade water. For sample preparation, $100 \mathrm{mg}$ of powdered form of shoot root and flowers were extracted in $25 \mathrm{~mL}$ volumetric flask with $5 \mathrm{~mL}$ of double distilled water using sonicator for $1 \mathrm{~min}$ and filter the extract. Again add $3 \mathrm{~mL}$ distill water and again extract the residue followed by filtration. Combine the filtrate and then allowe it to lyophilize to get powder form. The lyophilized powdered extract was then finally dissolved in $5 \mathrm{~mL}$ of HPLC grade water prior to HPLC analysis. All the extracts and standard stock solutions so made were finally filtered through $0.22 \mu \mathrm{m}$ pore size, Merck filter for HPLC analysis.

2.5. Calibration Curve and Linearity. Six different concentrations of both plantarenaloside and boschnaloside ranging from $15.6 \mu \mathrm{g} / \mathrm{mL}$ to $500 \mu \mathrm{g} / \mathrm{mL}$ were prepared from the standard stock solution. HPLC analysis was done on $10 \mu \mathrm{L}$ injection volume of each concentration in duplicate. The calibration curve was plotted by peak area versus concentration. The results are shown in Table 1.

2.6. Limit of Detection and Quantification. The limit of detection (LOD) and limit of quantification (LOQ) of plantarenaloside and boschnaloside were determined by signal to noise $(\mathrm{S} / \mathrm{N})$ ratio of three and ten, respectively, for the lowest detectable amount of both analytes. Results were given in Table 1.

2.7. Repeatability and Reproducibility. The measurements of interday and intraday variability were utilized to assess the repeatability and reproducibility of the developed method. The intra-day variability was performed under optimal conditions by means of six replicates of mixed standard. The percentage relative standard deviation RSD of both compounds was also calculated. The inter-day variability was examined for three days by performing six replicates each day. The precision of the method was determined at three different concentrations and results are given in Table 2. 


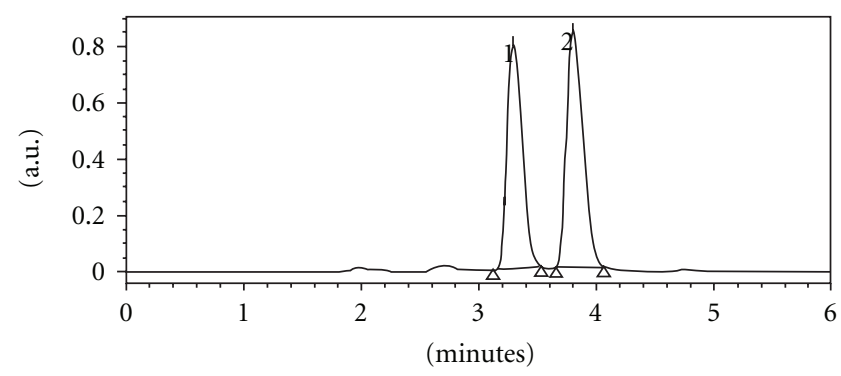

(a)

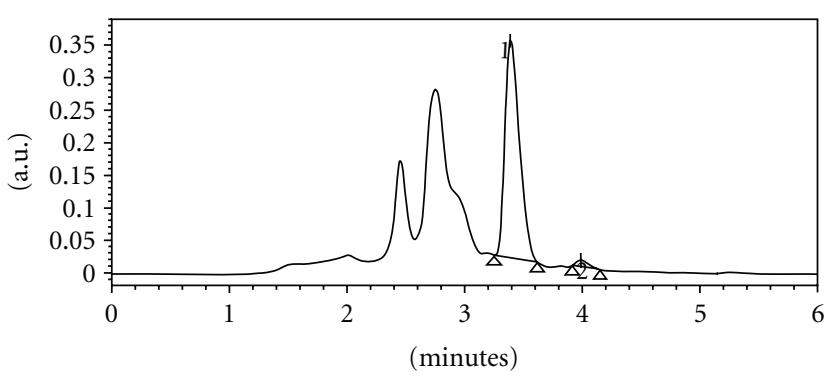

(c)

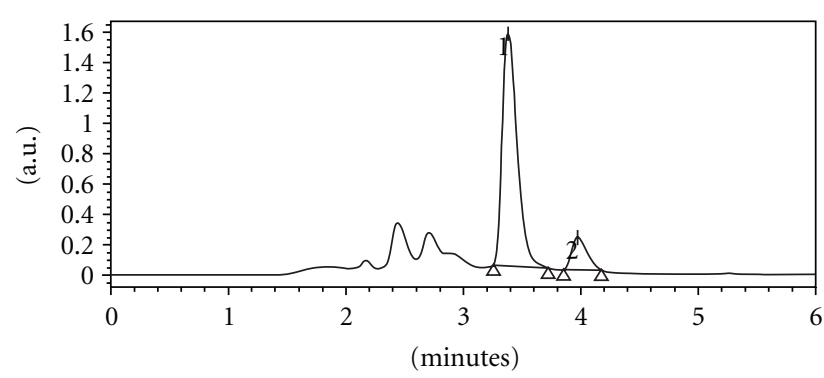

(b)

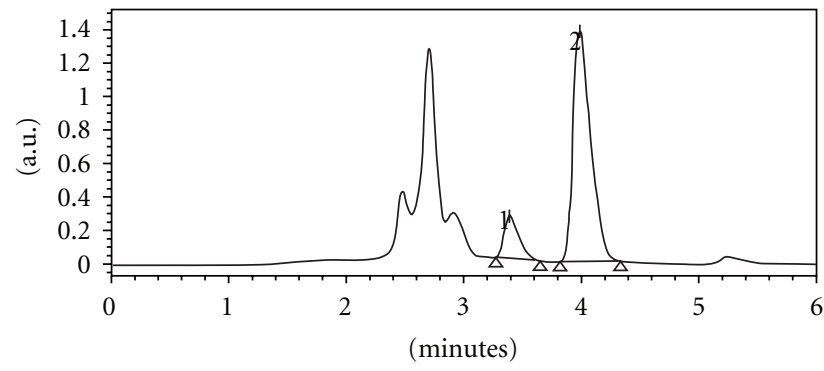

(d)

FIGURE 2: HPLC chromatograms (a) mixed standard of both plantarenaloside (1), and boschnaloside (2), (b) shoot portion, (c) root portion, and (d) flower portion.

\section{Result and Discussion}

In the HPLC method development, the mobile phase using methanol and water in ratio of $60: 40 \mathrm{v} / \mathrm{v}$ was found to have optimal influence in the resolution of the plantarenaloside and boschnaloside in plant samples. The chromatograms of root, shoot, and flower extracts of Incarvillea emodi are shown in Figure 2. This method is short, precise, and very suitable for detection and quantification of these iridoids.

The linear regression data for calibration curve of plantarenaloside and boschnaloside shows good linear relationship. The LODs $(S / N=3)$ for plantarenaloside and boschnaloside were 11.4 and $22.8 \mathrm{ng}$ and LOQs $(S / N=$ 10) for plantarenaloside and boschnaloside were found to be 38 and $76 \mathrm{ng}$, respectively. The precision data results for intra-day and inter-day variations of both iridoids were recorded in the range of $0.26-0.88 \%$ and $0.28-0.84 \%$, respectively, at three different concentrations levels $(125,250$ and $500 \mu \mathrm{g} / \mathrm{mL}$ ).

The HPLC analysis results show presence of plantarenaloside at concentrations of $6.78 \%, 1.19 \%$, and $0.87 \%$ in shoots, roots, and flowers, respectively, in dry weight basis of the plant powder form, while boschnaloside concentration in the respective plant dried powder form ranged in the order $0.88 \%, 0.03 \%$, and $6.12 \%$, respectively. This shows that plantarenaloside is the major iridoid in shoots and roots of Incarvillea emodi while boschnaloside is found to be in major amount in flowers. Aerial portion of Incarvillea emodi (shoots and flowers) contains combined 7\% approximately of these two iridoid glucosides.

\section{Conclusion}

A rapid and sensitive HPLC-DAD method for the determination and quantification of iridoid glucosides, plantarenaloside, and boschnaloside was developed. This is the first ever report on the quantification of these iridoid glucosides, from different parts of Incarvillea emodi. The present study shows that shoots contain major amount of plantarenaloside, while flowers contain major amount of boschnaloside. There is a presence of $6.78 \%$ of plantarenaloside in shoots and $6.12 \%$ of boschnaloside in flowers of Incarvillea emodi. This plant shows a very good example of dominance of individual iridoid glucoside plantarenaloside over boschnaloside in shoots and reverses in case of flowers. The method can serve to quantify such iridoid glucosides from other plants of same taxa or larger order while exploring role of these two iridoid glucosides as chemical markers in ecological context.

\section{Acknowledgments}

The authors are thankful to Mr. Upendra Sharma of NPP Division for guidance in method validation and Council of Scientific and Industrial Research (CSIR), New Delhi, India for financial grant to Project no. OLP-0033.

\section{References}

[1] B. Dinda, S. Debnath, and Y. Harigaya, "Naturally occurring secoiridoids and bioactivity of naturally occurring iridoids and secoiridoids. A review, part 2," Chemical and Pharmaceutical Bulletin, vol. 55, no. 5, pp. 689-728, 2007. 
[2] B. Dinda, D. Roy Chowdhury, and B. C. Mohanta, "Naturally occurring iridoids, secoiridoids and their bioactivity. An updated review, part 3," Chemical and Pharmaceutical Bulletin, vol. 57, no. 8, pp. 765-796, 2009.

[3] E. L. Ghisalberti, "Biological and pharmacological activity of naturally occurring iridoids and secoiridoids," Phytomedicine, vol. 5, no. 2, pp. 147-163, 1998.

[4] P. Bhandari, N. Kumar, B. Singh, A. P. Gupta, V. K. Kaul, and P. S. Ahuja, "Stability-indicating LC-PDA method for determination of picrosides in hepatoprotective Indian herbal preparations of Picrorhiza kurroa," Chromatographia, vol. 69, no. 3-4, pp. 221-227, 2009.

[5] V. N. Syrov, A. N. Nabiev, Z. A. Khushbaktova, U. V. Zakhidov, M. S. Maksudov, and Z. Saatov, "Hepatoprotector activity of iridoid glycosides with respect to heliotrine-induced acute toxic liver damage in mice," Pharmaceutical Chemistry Journal, vol. 33, no. 8, pp. 410-412, 1999.

[6] Z. W. Yu, H. Y. Zhu, X. S. Yang, Q. Y. Sun, and X. J. Hao, "Study on chemical constituents from Incarvillea arguta and their accelerating PC-12 cell differentiation," China Journal of Chinese Materia Medica, vol. 30, no. 17, pp. 1335-1338, 2005.

[7] C. S. Yuan, Q. Zhang, W. D. Xie, X. P. Yang, and Z. J. Jia, "Iridoids from Pedicularis kansuensis forma albiflora," Pharmazie, vol. 58, no. 6, pp. 428-430, 2003.

[8] A. L. Robert and S. R. Frank, "High performance liquid chromatographic analysis of Iridoid glycosides from Penstemon rydbergii varieties," Phytochemical Analysis, vol. 2, pp. 35-37, 1991.

[9] H. J. Li, P. Li, and W. C. Ye, "Determination of five major iridoid glucosides in Flos Lonicerae by high-performance liquid chromatography coupled with evaporative light scattering detection," Journal of Chromatography A, vol. 1008, no. 2, pp. 167-172, 2003.

[10] M. Li, R. Zhang, C. Li, P. Fan, Q. Zhang, and Z. Jia, "Development of a validated HPLC-PAD-APCI/MS method for the identification and determination of iridoid glycosides in Lamiophlomis rotata," Analytical Methods, vol. 2, no. 6, pp. 714-721, 2010.

[11] N. Singh, A. P. Gupta, B. Singh, and V. K. Kaul, "Quantification of picroside-I and picroside-II in Picrorhiza kurroa by HPTLC," Journal of Liquid Chromatography and Related Technologies, vol. 28, no. 11, pp. 1679-1691, 2005.

[12] J. R. D. A. Silva, A. C. F. Amaral, C. V. Da Silveira, C. M. Rezende, and A. C. Pinto, "Quantitative determination by HPLC of iridoids in the bark and latex of Himatanthus sucuuba," Acta Amazonica, vol. 37, no. 1, pp. 119-122, 2007.

[13] L. Yang, Y. Wang, L. Wang, H. Xiao, Z. Wang, and Z. Hu, "Rapid quantification of iridoid glycosides analogues in the formulated Chinese medicine Longdan Xiegan Decoction using high-performance liquid chromatography coupled with mass spectromentry," Journal of Chromatography A, vol. 1216, no. 11, pp. 2098-2103, 2009.

[14] A. Rana, D. Dhyani, A. Gulati, and H. P. Singh, "Isolation of two major iridoid glucosides from Incarvillea emodi," Natural Product Research, vol. 25, no. 10, pp. 1014-1017, 2011.

[15] A. Bianco, M. Massa, J. U. Oguakwa, and P. Passacantilli, "5deoxystansioside, an iridoid glucoside from Tecoma stans," Phytochemistry, vol. 20, no. 8, pp. 1871-1872, 1981.

[16] O. Sticher and O. Salama, "Iridoid glucosides from Euphrasia rostkoviana," Planta Medica, vol. 42, no. 2, pp. 122-123, 1981. 


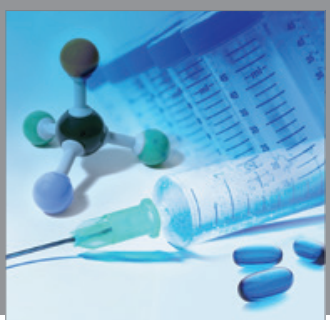

International Journal of

Medicinal Chemistry

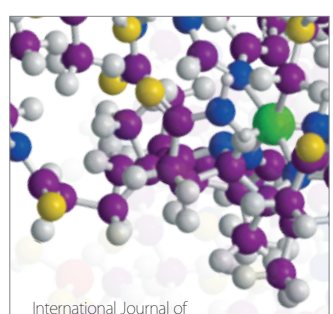

Carbohydrate Chemistry

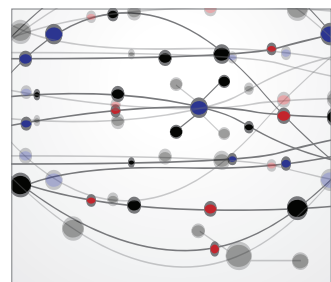

The Scientific World Journal
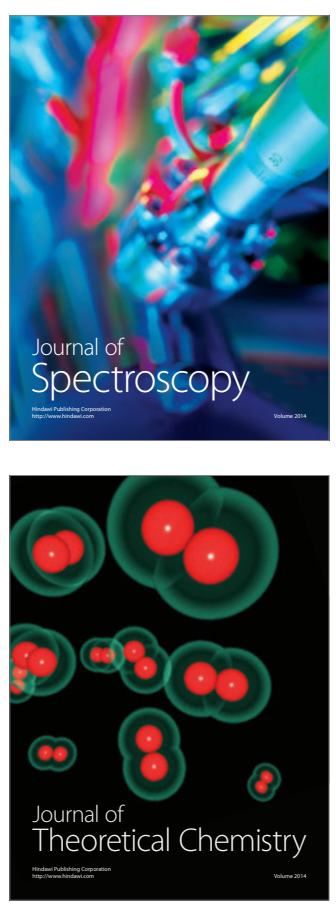
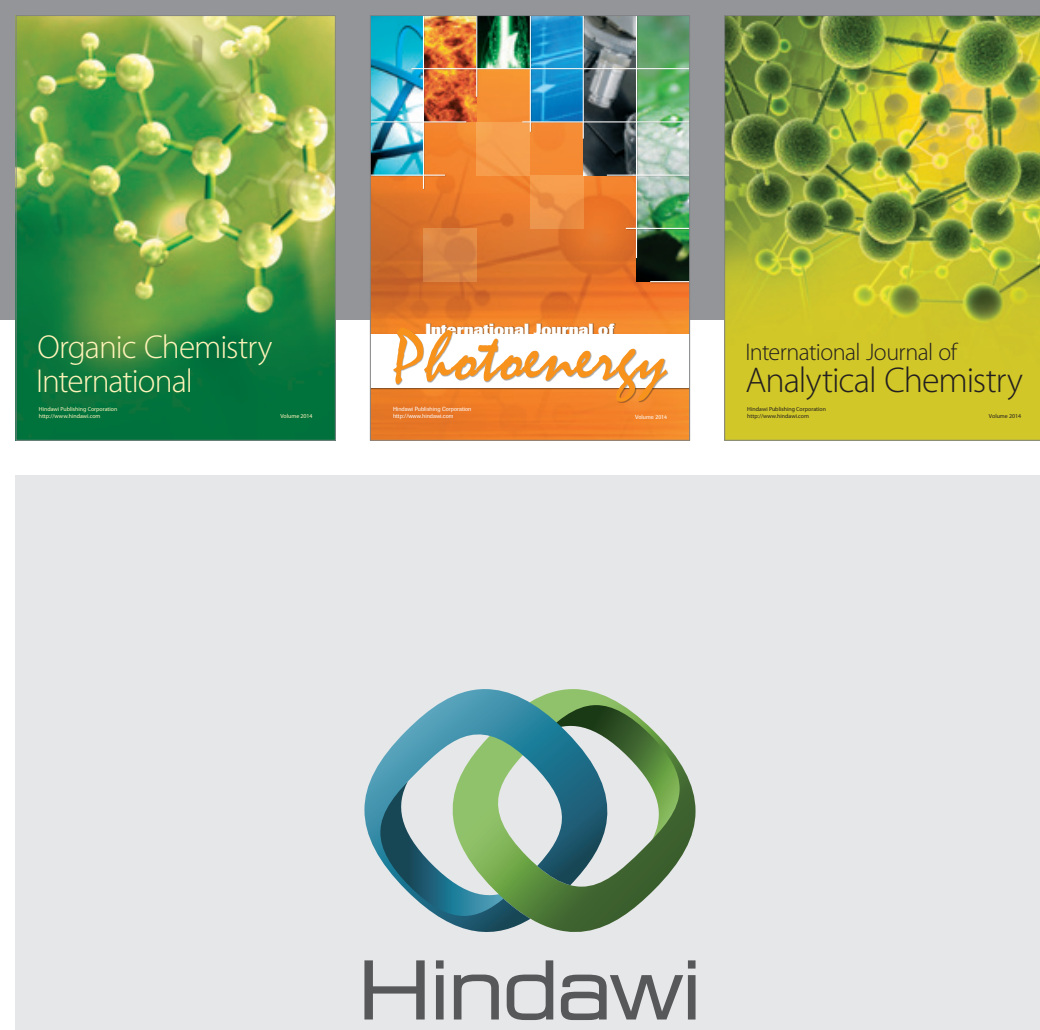

Submit your manuscripts at

http://www.hindawi.com
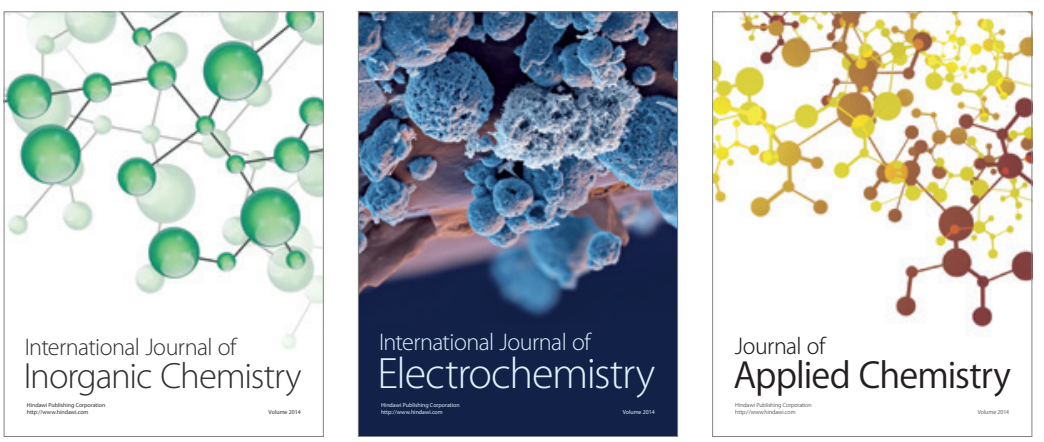

Journal of

Applied Chemistry
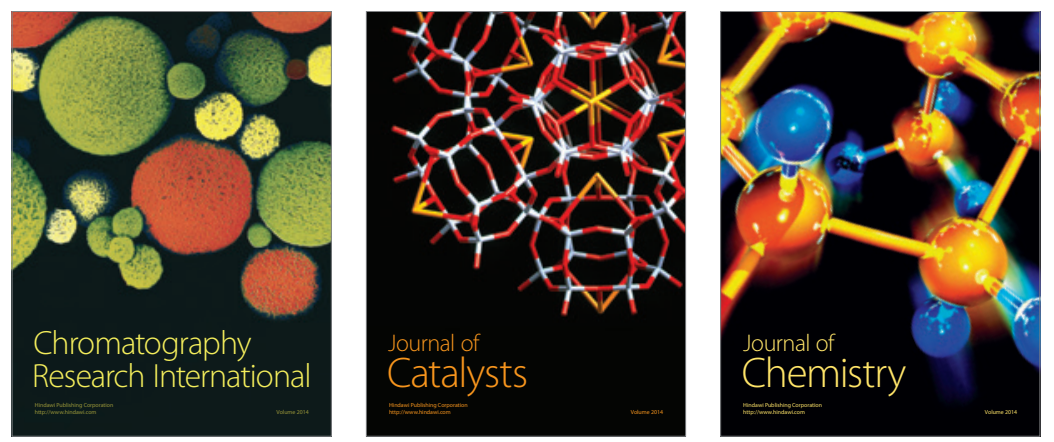
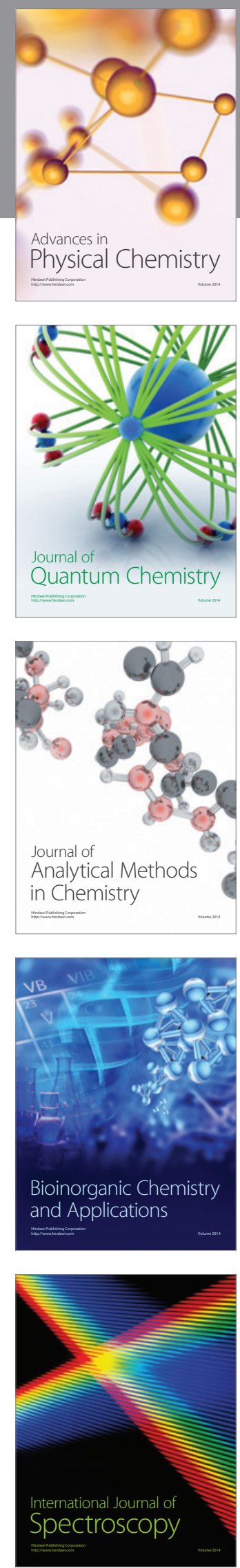